\title{
Numerical and analytical simulation of ballistic projectile penetration due to high velocity impact on ceramic target
}

\author{
Amin Moslemi Petrudi, Khodadad Vahedi, Masoud Rahmani \\ Department of Mechanical Engineering, Tehran University, Iran \\ amin.moslemi2020@gmail.com, http:/ /orcid.org/0000-0002-5928-0479 \\ kbvahedi@ibu.ac.ir \\ msrahmani@ibu.ac.ir, bttp://orcid.org/0000-0002-0519-0670
}

MohammadAli Moslemi Petrudi

Department of Maritime Engineering, Amirkabir University, Tehran, Iran

mamp_1394@yahoo.com

\begin{abstract}
Simulation and analysis of the projectile impact and penetration problem and its effects are among the practical topics that can be used to design bulletproof panel and military equipment, construction of impact and penetration resistant structures, design of projectiles with appropriate penetration strength and high performance noted. One of the most important parameters affecting penetration is the impact velocity of the projectile. The mechanism of penetration varies in different speed ranges. In this paper, Ansys Autodyn software is used for penetration simulation. The simulation carried out in this study is based on the accuracy and physical conditions of the problem and the compatibility of numerical simulation with the governing analytical relations indicates the validity and accuracy of the assumptions made in the simulation. In this study, we selected materials such as material behavior, grating, contact surfaces, and controls, as well as collision of the blunt projectile with angles of $0^{\circ}, 15^{\circ}, 30^{\circ}, 45^{\circ}$ by of high velocity impact 1000 $\mathrm{m} / \mathrm{s}$ with the same mass and diameter and shape of the projectile nose and properties. Ceramic materials are discussed. The result of the numerical simulation comparison shows relatively good agreement between them.
\end{abstract}

KeYwords. Ceramic; Penetration; Blunt projectile; High velocity impact.

\section{OPEN ACCESS}

Citation: Petrudi, A. M., Vahedi, K., Rahmani, M., Petrudi, M.M., Numerical and analytical simulation of ballistic projectile penetration due to high velocity impact on ceramic target, Frattura ed Integrità Strutturale, 54 (2020) 226-248.

Received: 12.05 .2020

Accepted: 05.09 .2020

Published: 01.10 .2020

Copyright: (C) 2020 This is an open-access article under the terms of the CC-BY 4.0 , which permits unrestricted use, distribution, and reproduction in any medium, provided the original author and source are credited.

\section{INTRODUCTION}

$\mathrm{T}$ he projectile penetration has been a complex, nonlinear, transient phenomenon, and research on it has begun many years ago and is still ongoing. Today, in addition to military applications, its civilian uses, such as the manufacture of satellite Defence equipment, the protection of nuclear reactors, the transportation of hazardous materials, the 
retrofitting of helicopters, airplanes, etc., have increased the development of this science. At low velocities, various theories have been presented to analyze the impact and failure process. But at high velocities, often the phenomenon of projectile shattering and part of the target occurs. Other important parameters in the penetration and infiltration process are the angle of impact, material property, projectile nose shape, projectile thickness, and target [1]. The lack of pivotal symmetry in the oblique collision problem has made the analytical study of this issue very complex. Therefore, the problem of the collision has so far been investigated more extensively by laboratory and semi-empirical analysis as well as numerical and computer simulations. The projectile and the target are two key components of the infiltration process. The use of different projectiles such as AP kinetic energy projectiles, long rod projectiles, and segmented rods has been developed, in contrast, different types of armor such as reactive armor, composite metal ceramic multilayer armor, composite ceramic, metal multilayer, have also been developed [2]. Minimum weight is one of the main criteria in armor design. Therefore, it is important that when the weight of the armor decreases, its penetration resistance remains high. As a result, it is necessary to use materials for the manufacture of armor that have a low weight and high resistance to penetration. Here is an example of ceramics used in the manufacture of armor that is both lightweight and has a high penetration resistance. Among the steps taken in the design of the armor to reduce the weight of the armor are the following:

1) Use spaced or stacked armor made of two or more aluminum or steel plates.

2) The use of composite armor uses ceramics as a front panel (a screen directly exposed to projectile impact) and an alloy or metal plate as a back panel, and the two plates are bonded together.

Multilayer targeting is done to improve penetration resistance and weight loss by using materials with different mechanical properties. Also, the simplicity of construction and avoidance of damage to the entire target in the infiltration can be the reasons for multilayer targets. Tab. 1 shows the penetration and impact studies of high velocity projectiles on ceramic targets [3].

\begin{tabular}{lcc}
\hline \multicolumn{1}{|c}{ Author(s) } & \multicolumn{1}{c}{ Characteristic } & Years \\
\hline Florence et al. [4] & $\begin{array}{c}\text { Interaction of projectiles } \\
\text { and composite armor } \\
\text { long rod projectile impact } \\
\text { on ceramic }\end{array}$ & 1967 \\
X. Zhang et al. [5] & $\begin{array}{c}\text { penetrating ceramic } \\
\text { composite target } \\
\text { R.-c. Yi et al.[6] }\end{array}$ & 2017 \\
Brown et al.[7] & $\begin{array}{c}\text { bullet into ceramic armor } \\
\text { Penetration of confined } \\
\text { ceramics targets }\end{array}$ \\
Das et al.[8] & $\begin{array}{c}\text { Ballistic performance } \\
\text { evaluation of ceramic tiles } \\
\text { Oblique Penetration of } \\
\text { Blunt Projectile into } \\
\text { Ceramic-Aluminum Target }\end{array}$ & 2017 \\
Moslemi Petrudi al.[9] & 2018 \\
\hline
\end{tabular}

Table 1: Studies on the impact and penetration of ceramic targets.

\section{THE PHENOMENON OF IMPACT AND PENETRATION}

$\mathrm{T}$

he impacts phenomenon is an interdisciplinary phenomenon and therefore deals with various phenomena such as elastic and plastic waves propagation, heat and mass transfer, hard work, friction, hydrodynamic flow, different fracture modes, fracture resistance, abrasive impact. On the other hand, due to the lack of access to some of the properties of the material in the high strain rate, this phenomenon is very complex and presents many problems [11-12]. Numerous scientists have been taking this step seriously over the last fifty years and have prepared this complex subject for comprehension and investigation by numerous empirical and analytical methods or numerical simulations. Classification by purpose type in different types such as The semi-infinite goal is a thick and thin target and can be accomplished in a variety of metallic, ceramic, and composite purposes, depending on the type of target material, while the target can be single-layered or multi-layered. Classification can be done by projectile type and shape. The projectiles can be nose-shaped in the form of a hemispherical, ogive, blunt, or conical [13-14]. The projectiles can also be short or long cylinders and can be made of one 
material in one piece or several materials in multi-laminated. Fig. 1 shows the Properties of ceramics and Tab. 1 shows the approximate velocity ranges and Tab. 2 shows the collisions based on impact velocity. The velocity ranges, of course, are merely the basis of comparison and the transition processes between them are quite flexible because the process of changing the forms due to impact loading depends on many parameters in addition to velocity [15].

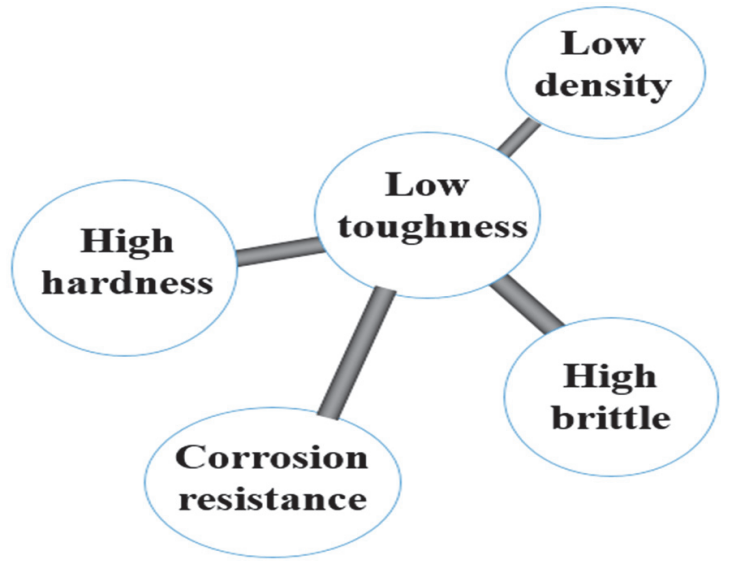

Figure 1: Properties of ceramics.

\begin{tabular}{lcc}
\hline \multicolumn{1}{c}{ The type of behavior } & Damage Number & Velocity $(\mathrm{m} / \mathrm{s})$ \\
Elastic behavior & 0.00001 & 0.5 \\
Plastic behavior & 0.001 & 5 \\
Ultrasonic penetration & 40 & 1000 \\
Hydrodynamic behavior & 1000 & 5000 \\
Explosive impact & 10000 & 15000 \\
\hline
\end{tabular}

Table 2: The approximate velocity ranges [10].

\begin{tabular}{lcc}
\hline \multicolumn{1}{c}{ The type of behavior } & $\begin{array}{c}\text { Velocity Range } \\
(\mathrm{m} / \mathrm{s})\end{array}$ & $\begin{array}{c}\text { The type of Velocity } \\
\text { Elastic waves propagation }\end{array}$ \\
$\begin{array}{l}\text { Elasto-plastic waves } \\
\text { propagation }\end{array}$ & $100-1000$ & Low velocity's \\
$\begin{array}{l}\text { Elasto-plastic propagation } \\
\text { or hydrodynamic behavior } \\
\text { Hydrodynamic behavior }\end{array}$ & $1000-3000$ & Average velocity's \\
& More than 3000 & High velocity's \\
\hline
\end{tabular}

Table 3: The collisions based on impact velocity [10].

\section{Types of Failure to Penetration}

hen a projectile hits a target of limited thickness, there are several possible types of damage. The mechanism of failure depends on various factors such as material properties, geometry, and velocity of impact. Explanation of some basic concepts of penetration mechanics [16]: 
* Kinetic Energy Launcher: A projectile that has high kinetic energy due to its high speed and mass and is therefore highly efficient in creating a cavity in the target.

* Impact of the projectile (cross-section) diameter: The projectile diameter is one of the important and effective parameters in penetration. Increasing projectile diameter results in an increased cross-sectional area, and this factor reduces ballistic speed in ceramics that are brittle and exhibit brittle behavior. In other words, due to the ceramic brittle, the higher the cross-sectional area, the higher the surface of the ceramic being broken at the first moment of impact, thus facilitating projectile penetration.

* Mushrooming projectile shape: The flow of projectile head material after it hits the target in a radial direction and increases the projectile cross-section.

* Ricochet: The projectile crosses the surface of the striker without stopping or penetrating it.

* Fracture due to initial stress wave: occurs when the initial stress wave in an impacted zone exceeds the ultimate compressive strength $\sigma_{\mathrm{uc}}$ of the material. This can occur in weak and low-density targets.

* Radial fracture at the frontal side: occurs in the frontal side of the target. This is conceivable in brittle target elements whose tensile strengths are substantially lower than their corresponding compressive values, such as ceramics.

* Spalling and Scabbing is a tensile material failure due to the tensile reflection of the initial compressive transient waves from the distal side (far side) of the target and is a common phenomenon under explosive loading. Failure by spalling can occur on either the front or back of a target and is characterized by the formation of petals or ejects. Scabbing has a similar appearance, but the fracture is produced by deformation and its surface is determined by local inhomogeneity and/or anisotropies that may exist in the rolling direction.

* Petaling: is produced by high radial and circumferential tensile stresses after the passage of the initial wave occurring near the tip of the penetrator. This deformation is the result of bending moments created by the forward motion of the plate material being pushed ahead of the striker, and by inhomogeneity or planes of the weakness of the target. It is most frequently observed in thin plates struck by ogive or conical bullets at relatively low impact velocities or by blunt projectiles near the ballistic limit.

* Fragmentation: occur when the projectile strikes at high velocities on the brittle targets like ceramics and targets made of heterogeneous materials like concrete.

* Ductile failure or the ductile hole enlargement: the impact impulse overcomes the peripheral dynamic shear strength of the target material, pushing it outward and toward the impact surface to form a crater that is much larger than the projectile diameter. At the same time, the projectile pushes into the target, and there are hydrodynamic erosion and inversion of the penetrator material against the preceding face of the target.

* Plugging: develops as the result of a nearly cylindrical slug of approximately the same diameter as the bullet being set in motion by the projectile. Failure occurs due to large shears produced around the moving slug. The heat generated by the shear deformation is restricted to a narrow annulus in which it decreases the material strength resulting in instability and is called an adiabatic shearing process. Plugging is most frequently found when blunt penetrators strike intermediate or thin, hard target plates. Its presence is sensitive to velocity and the angle of obliquity of pointed projectiles. Shear plugging is generally observed for thick targets, particularly with high strength materials. In these instances, an intense shear band may be observed intersecting a tensile opening at the stretched rear surface.

* Discing failure: in the case of discing, shear cracks develop in the plane of the plate as a consequence of in-plane shear stresses induced by bending. Both metallurgical inclusions and inhomogeneity in the plane 
of the plate, as well as adiabatic thermal softening effects associated with the high rate of deformation, contribute to discing failure.

* Dishing: occurs in targets of thinner plates where bending is favored. The stretching of the sheet can lead to tensile failures at the edges with a plug ejected, or the plug folded away attached to one of the petals, or necking and tearing in the form of a star pattern from the center of impact. This last mechanism involves bending and ironing the flat of the petals as well as radial stretching.

Fig. 2 shows different failure modes in impacted plates and Fig. 3 shows the effect of the impact below the ballistic limit on the projectile.

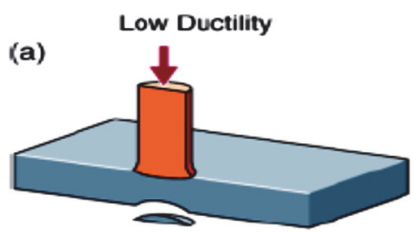

Spall fracture

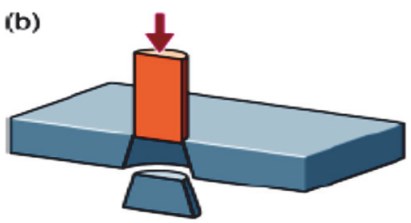

Plugging

(c)

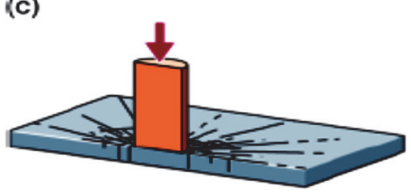

Radial fracture

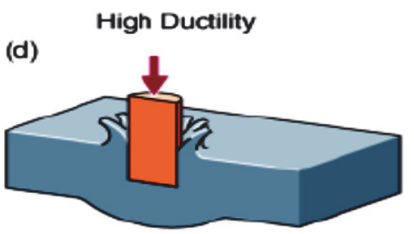

Petaling (frontal)

(e)

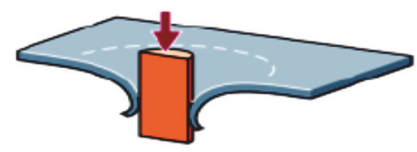

Petaling (rearward)

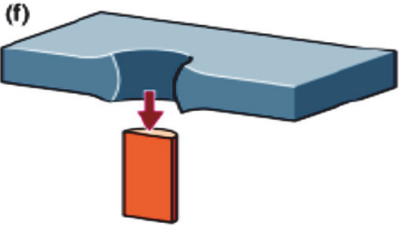

Ductile hole enlargement

Figure 2: Different failure modes in impacted plates [10].

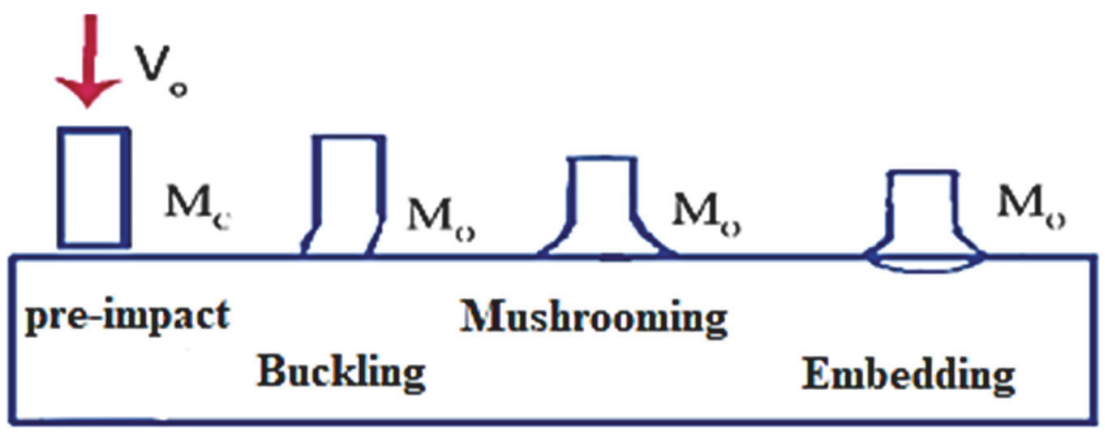

Figure 3: The effect of the impact below the ballistic limit on the projectile [10].

\section{EFFECTIVE PROJECTILE AND TARGET PARAMETERS IN THE PENETRATION PROCESS}

$\mathrm{P}$

arameters such as material and mechanical properties, nose shape, projectile diameter, velocity, mass, and angle of impact are important parameters of the projectile penetration process, which is the most important parameter in determining the type of failure [17-18].

1) Mechanical Properties and Material of the Projectile: One of the properties considered in ballistic penetration is the mechanical and material properties of the projectile. The projectile can generally be classified as follows. 
* Soft projectiles: are projectiles that are deformed by impact.

* Rigid Projectiles: These are projectiles that do not deform due to the target's hardness.

Soft projectiles are used for special applications. They are usually made of aluminum and copper with a very thin shell [1920]. These projectiles, after they hit the target, undergo severe deformation and cover a large area of the target, and in the event of an explosion, the explosives inside the projectile destroy the large area of the target but have little penetration depth. Rigid projectiles are usually made of high-alloy steels made of carbon, silicon, nickel, and alloys [21]. Most projectiles are rigid projectiles. The main criteria of these projectiles are resistance to deformation in the target encounter and are designed to penetrate a specific target that differs in the method of manufacture, type and percentage of alloys used [22-23].

2) Projectile Mass: The higher the kinetic energy of the projectile, the greater the projectile's penetration into the target.

Given the equation of the initial energy of the projectile $\left(E=\frac{1}{2} M_{P} V^{2}\right)$

The mass of the projectile (similar to the velocity of impact) is of particular importance in how much and how it penetrates.

3) Impact Angle: The angle between the projectile axis and the target surface is the impact angle and can be divided into normal and oblique impacts depending on the impact angle. Normal collision in which the projectile axis and the target plane are perpendicular to each other and the collision is oblique. The angularity of the collision increases the ballistic speed of the target. Also, in inclined collisions, the projectile is rotated and redirected within the target and it is possible to ricochet the projectile.

4) Impact velocity: Most impact mechanics researchers consider impact velocity the most important factor in how projectiles penetrate targets. In laboratories, these velocities are usually caused by light gas guns. In this limit, most factors lose even the material resistance of their impact, and density plays a major role in the diffusion process. At these velocities, the effects of the initial angle on the collision can be ignored to analyze the penetration on the oblique collision, and the penetration process is similar to that of the normal collision. However, the effective thickness is used instead of the target thickness.

5) Nose shape: There are usually projectiles with different nose shapes. Among these can be pointed projectiles with flat nose, hemispherical, conical, and ogive shown in Fig. 4.

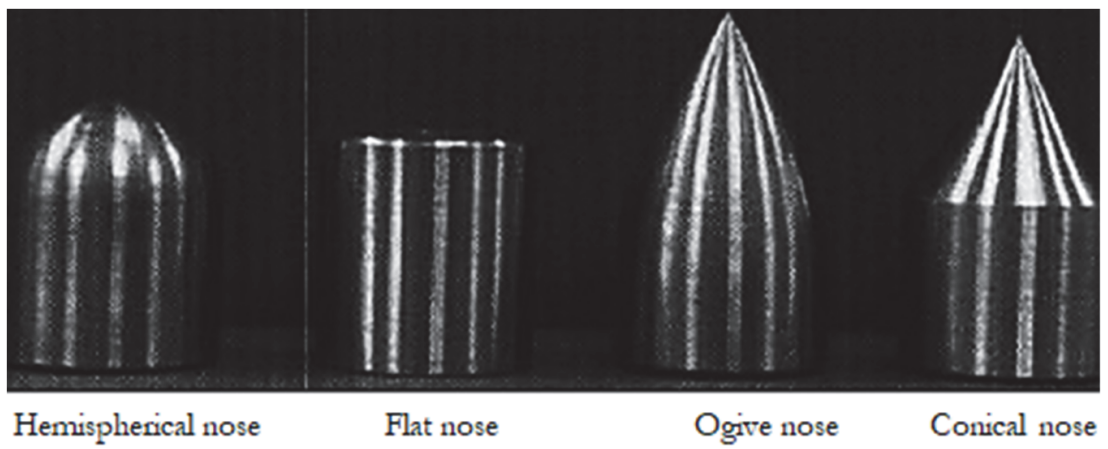

Figure 4: Different forms of the projectile nose [10].

Parameters such as material, mechanical properties, total thickness, number of layers, and their placement and support conditions are important parameters in the penetration process. Other parameters of the target, such as uniformity and homogeneity of the target, are also effective in the penetration process. The presence of cracks, cavities, or impurities in the target causes stress concentration in the impact area and severely reduces the target strength [24-25].

1) Effects of Multilayer Targeting: One of the effective parameters in the penetration process is the number of layers and how these layers are placed in the target set. The multilayer technique is usually used to improve the target's resistance to penetration and weight loss, using materials with different mechanical properties. These layers can be adjacent to or separated from each other (at a distance). In addition to improving penetration resistance, other reasons for multilayer targeting include the ease of constructing and repairing the target and preventing the entire target from being destroyed when the penetration is minor. Using a hard layer in front of the armor that is highly 
resistant to impact, along with a soft layer that is highly absorbable (behind the target) is a very good combination to improve the penetration resistance of the armor or target body.

2) Target Thickness: Target-thickness and the ratio of projectile diameter to target thickness are important parameters in penetration resistance and type of fracture and selective analytical model of penetration. As the thickness increases, ballistic resistance to penetration also increases.

3) Target material: One of the most important factors in determining the penetration process and type of failure is the target material. Parameters such as hardness, density, yield stress, ultimate stress (stress-strain equation), and target material depend.

4) Target hardness: one of the important and effective parameters in the penetration phenomenon. According to research, increased ceramic hardness results in increased resistance to target penetration. An important feature of metal armor is that they have high hardness. It should be explained that there is no simple relationship between hardness and resistance to penetration.

5) The target density: proportional to the dynamic energy and has a linear relationship. In other words, as the target density increases, its resistance to penetration increases.

6) The yield stress and ultimate stress of the target: directly penetration the target's resistance to projectile penetration, and in the analytical study of the penetration process it is assumed that at failure, the stress created at the target is equal to the target equal to the stress. In and around the collision zone, the deformations are plastic and permanent. Also, the stresses during penetration are far more than the elastic yield stress. Stress-strain behavior is shown in Fig. 5 and Comparison of the properties of ceramic, metal, and polymer shown in Fig. 6.

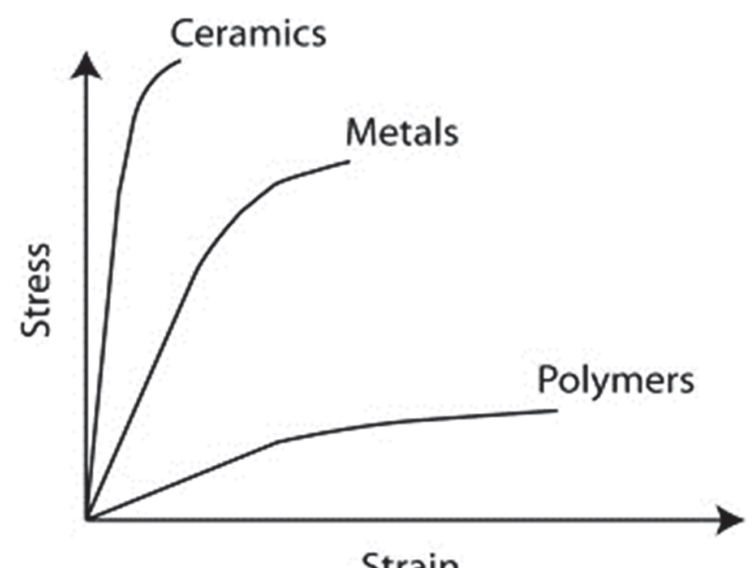

Strain

Figure 5: Typical Stress-strain Curve for the three classes of materials [16].

\begin{tabular}{|l|c|c|c|}
\hline Hardness & Ceramic & Metal & Polymer \\
\hline Elastic modulus & High temperature \\
strength
\end{tabular}

Figure 6: Comparison of the properties of ceramic, metal, and polymer [22]. 
Awerbuch and Bodner in 1973 divided bullet penetration into metal targets into three main parts [26]:

* Part One: In this section, only compressive and inertial forces are applied to the projectile and no shear occurs.

* Part Two: In this section shear, compressive and inertial forces are applied to the projectile and due to shear force, the plug begins to form.

* Part three: In this section, the only shear force is applied to the projectile and a plug is formed which is thrown out with the projectile from the back surface of the target.

Ravid and Bodner in 1994 divided the projectile penetration into the target into five stages [27]:

* Stage One: In this stage, the plastic penetrates dynamically and the plastic flow around the projectile is considered.

* Stage Two: In this section, the bulge formation is considered behind the target as the material moves backward.

* Stage Three: Develop a convexity behind the target.

* Stage Four: At this stage, the plug is formed behind the target and exits.

* Stage Five: Exit the projectile from behind the target.

\begin{tabular}{|c|c|c|c|c|c|c|}
\hline Material & $\begin{array}{l}\text { Thermal expansion } \\
\text { coefficient } \\
\qquad\left(\frac{1}{{ }^{\circ}}\right) 10^{-6}\end{array}$ & $\begin{array}{c}\text { Tensile } \\
\text { strength }(\mathrm{MPa})\end{array}$ & $\begin{array}{c}\text { Flexural } \\
\text { strength }(\mathrm{MPa})\end{array}$ & $\begin{array}{l}\text { Hardness } \\
\text { (GPa) }\end{array}$ & $\begin{array}{c}\text { Elastic } \\
\text { coefficient } \\
(\mathrm{GPa})\end{array}$ & $\begin{array}{l}\text { Density } \\
\left(\mathrm{g} / \mathrm{cm}^{3}\right)\end{array}$ \\
\hline $\mathrm{Al}_{2} \mathrm{O}_{3}$ & 4.2 & $280-300$ & - & $9.4-14.5$ & 380 & 3.99 \\
\hline AIN & 7.4 & 125 & $350-400$ & $10-11$ & 310 & 3.26 \\
\hline $\mathrm{B}_{4} \mathrm{C}$ & 5.6 & 350 & 500 & $20-25$ & 420 & 2.52 \\
\hline $\mathrm{SiC}$ & 3.8 & $180-280$ & $350-450$ & $20-26$ & 400 & 3.21 \\
\hline
\end{tabular}

Table 4: Mechanical Properties of Armor ed Ceramics [26].

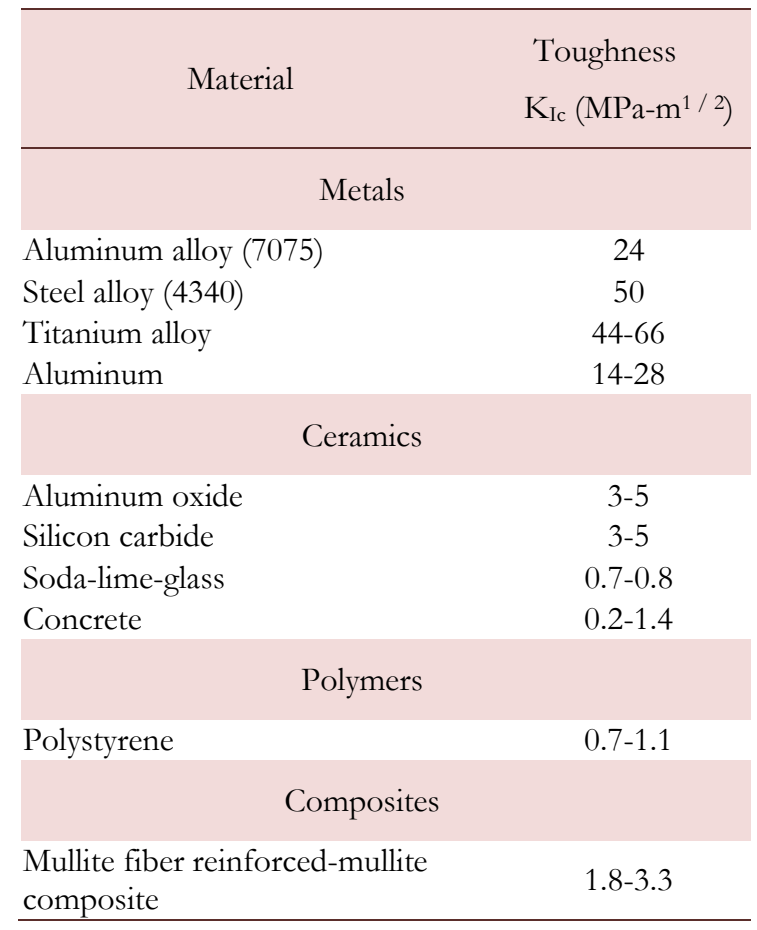

Table 5: The amount of fracture toughness in different materials [24]. 
Tab. 4 Mechanical Properties of Armored Ceramics and Tab. 5 The amount of fracture toughness in different materials and percentage Contribution of research on reinforcements and ceramics is shown in Fig. 7.

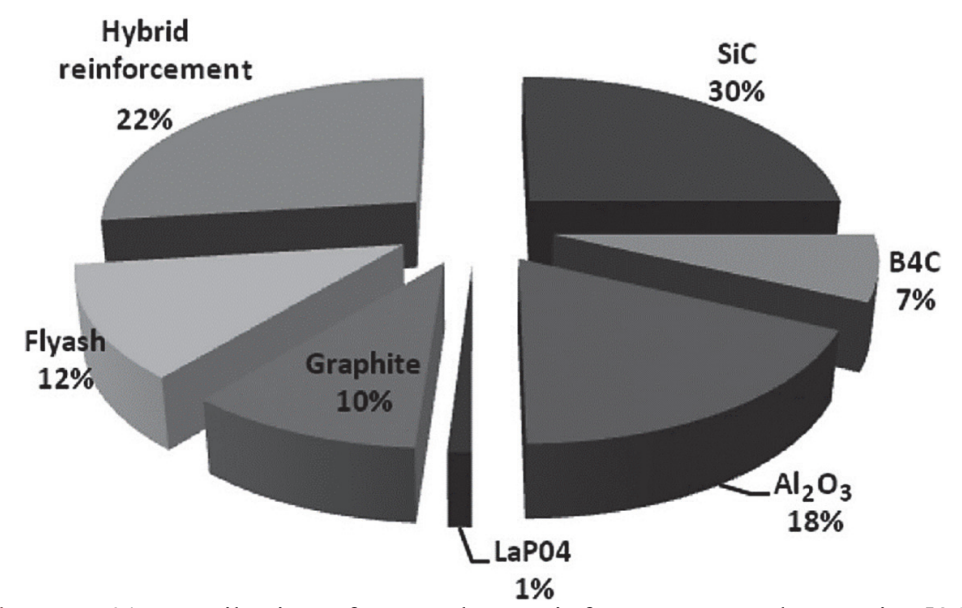

Figure 7: \% Contribution of research on reinforcements and ceramics [21].

\section{ANALYTICAL MODELS OF PENETRATION ON CERAMICS}

his section examines the theories and models presented in the field of ceramics penetration.

\section{Model by Johnson Cook}

The relationship proposed by Johnson and Cook to express the effects of plastic work, plastic strain rate, and temperature on yield stress is given by the Eqn. (1):

$$
\sigma=\left[A+B \varepsilon^{n}\right]\left[1+C \ln \dot{\varepsilon}^{*}\right]\left[1-T^{*} m\right]
$$

where $A, B, C, n, m$ the constants of the material and $\varepsilon$ the strain of the plastic equivalent $\dot{\varepsilon}^{*}$ are the dimensionless parameters of the strain rate of the plastic $\dot{\varepsilon}^{*}=\dot{\varepsilon} / 1.0 s^{-1}$ to be defined. $T^{* m}$ The dimensionless parameter is the temperature, which is calculated from the Eqn. (2).

$$
T^{* m}=\frac{T-T_{\text {Room }}}{T_{\text {Melt }-} T_{\text {Room }}}
$$

In this model, the effects of plastic strain rate overtime on yield stress are considered, but in Steinberg's model, it is ignored. The reason is the difference in the range of use of these models. In the experiments performed by Johnson and Cook to calculate the coefficients used in this model, the highest plastic strain rate was $400 s^{-1}$ but in the Steinberg experiments, they were more than $10^{5} s^{-1}$ because of their attention to explosive loading and the extremely high velocity impacts. The equivalent plastic strain is obtained from Eqn. (3):

$$
\varepsilon=\sum \dot{\varepsilon} \Delta t
$$




$$
\dot{\varepsilon}=\left\{\frac{2}{9}\left[\left(\dot{e}_{r}-\dot{e}_{z}\right)^{2}+\left(\dot{e}_{z}-\dot{e}_{\theta}\right)^{2}+\left(\dot{e}_{\theta}-\dot{e}_{r}\right)^{2}\right]+\frac{1}{3} \dot{y}_{r z}\right\}^{\frac{1}{2}}
$$

$\dot{e}_{r}, \dot{e}_{\theta}, \dot{e}_{z}$ The strain rates are plastic and $\dot{j}_{r z}$ the shear rates are plastic [18].

\section{Model by Felorance}

One of the most famous is the analytical model in which the penetration of composite targets (metal-ceramics) is investigated. The basis of his model was that ceramics distribute force over a wide area and the backs will absorb all the energy from the collision. In this model, ballistic limit velocity is predicted by Eqn. (5). The projectile approach to the metalceramic target and our relationship between the variables are shown in Fig. 8 [4].

$$
\begin{aligned}
& V_{p}=\sqrt{\frac{\varepsilon_{2} \sigma_{2} h_{2}}{91 M_{p} f(a)}} \\
& f(a)=\frac{M_{p}}{\left[M_{p}+\left(\rho_{1} b_{1}+\rho_{2} b_{2}\right) \pi a^{2}\right] \pi a^{2}} \cdot a=a_{p}+2 b_{2}
\end{aligned}
$$

Variables in the above relationships are: $V_{p}$ : ballistic velocity prediction, $\varepsilon_{2}:$ backing failure strain, $\sigma_{2}:$ ultimate tensile strength of the backing layer, $\rho_{2}$ : backing layer density, $h_{2}$ : backing thickness, $\rho_{1}$ : front panel density, $h_{1}$ : front panel thickness, $M_{p}$ : projectile mass. A projectile collision into Target and the formation of ceramic cone shown in Fig. 8.

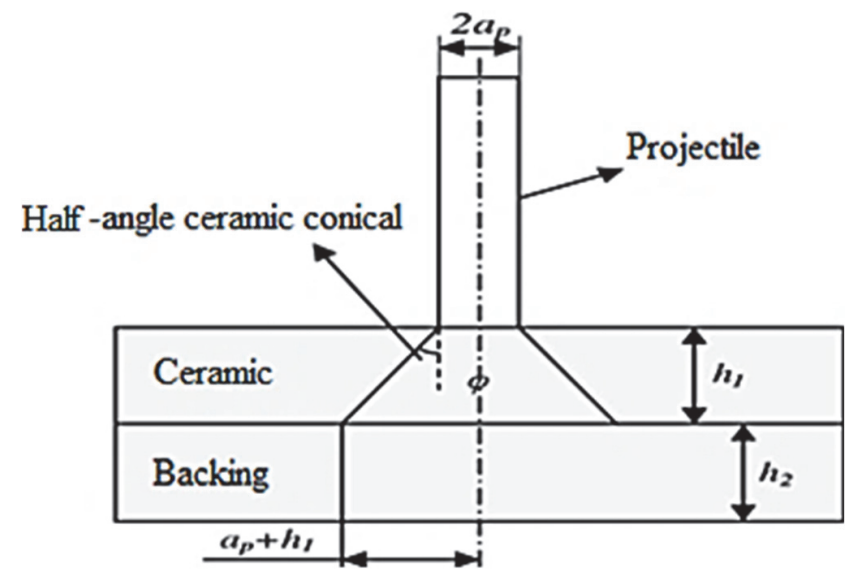

\section{Model by Zaera}

Figure 8: Projectile collision into Target and the formation of ceramic cone [10].

The Zaera model is a method for analytical simulation of the vertical impact of small and medium caliber projectiles on metal-ceramic armor. In this model, projectile erosion and mass reduction are considered. The Tate equation has been used to describe projectile erosion. The response of the metal backing is based on the Woodward method [24]. It is important to note here that Tate penetration is intended to penetrate metallic targets in this model, although it can also be applied to ceramics provided that the conditions and properties of the target are replaced in the equations. Tate equations for projectile modeling are as follows:

$$
\begin{aligned}
& Y_{p}+\frac{1}{2} \rho_{p}(V-U)^{2}=R_{T}+\frac{1}{2} \rho_{T} U^{2} \\
& \frac{d l}{d t}=-(V-U)
\end{aligned}
$$




$$
\frac{d v}{d t}=-\frac{Y_{p}}{\rho_{p}}
$$

where $Y_{p}$ is the projectile strength, $R_{T}$ is the target penetration strength, $\rho_{p}$ and $\rho_{r}$ are projectile and target densities. $\mathrm{L}$ The length of the projectile at any time interval, its velocity $\mathrm{V}$, is the penetration velocity $\mathrm{U}$. One of the most important stages of the ceramic response under impact is the initial phase immediately after impact and contact with the projectile. In the early microseconds after a ceramic collision, a compressive wave begins to advance the surface. This will cause the cone to crack and move in the direction of impact. And it goes forward in the target material. These cracks are caused by the tensile stress waves created at the edge of the collision. This conical area is trapped between the metal backing and the projectile. The assumption is that cracks occur when waves of pressure pass through ceramic plates. The time required to create a crack is calculated from the following equation:

$$
t_{\text {conoid }}=\frac{h_{c}}{u_{\text {long }}}+\frac{h_{c}}{v_{\text {crack }}}
$$

where $h_{c}$ are the ceramic thickness $u_{\text {long }}$ the velocity of the longitudinal stress wave, and $v_{\text {crack }}$ the velocity of the wave in the radial crack. The linear momentum of the cone crack is calculated from (10):

$$
\frac{d p_{c}}{d t}=Y_{c} \pi \frac{D_{e q}^{2}}{4}-f_{b} \pi \mathrm{R}_{c t}^{2}
$$

$f_{b}$ The pressure on the joint surface of the target and projectile and $R_{c t}$ the radius of cone crack and $p_{c}$ linear momentum, $R_{c t}$ as determined by the following equation:

$$
\mathrm{R}_{c t}=\frac{D_{e q}}{2}+h_{c t} \cdot \tan \alpha
$$

where $h_{c t}$ is the actual thickness of the ceramic projectile head separator from the metal plate. The cone linear momentum is obtained by considering the velocity distribution $\mathrm{V}$ on the joint surface of the ceramic projectile and $\mathrm{W}$ on the joint surface of the ceramic backing layer by the following equation:

$$
\begin{aligned}
& \frac{d P_{c}}{d t}=\frac{\partial P_{c}}{\partial h_{c t}} \frac{\partial h_{c t}}{d t}+\frac{\partial P_{c}}{\partial R_{c}} \frac{\partial R_{c}}{d t}+\frac{\partial P_{c}}{\partial u} \frac{d u}{d t}+\frac{\partial P_{c}}{\partial w} \frac{d w}{d t} \\
& P_{c}=\pi \rho_{c} b_{c t}\left[U\left(\frac{D_{e q}^{2}}{16}+\frac{R_{c t}^{2}}{12}+\frac{D_{e q} R_{c t}}{12}\right)+w\left(\frac{D_{e q}^{2}}{48}+\frac{R_{c t}^{2}}{4}+\frac{D_{e q} R_{c t}}{12}\right)\right]
\end{aligned}
$$

To model the behavior of the metal backing layer according to the Woodward method the energy lost from the projectile during the tensile and flexural plastic deformation of the back material is determined from the following equation:

$$
E_{p}=\pi h_{b} \delta Y_{b}\left(\frac{2}{3} h_{b}+\frac{1}{2} \delta\right)
$$

where $h_{b}$ is the thickness of the backing plate, $\delta$ is the deformation of the central plate, and $Y_{b}$ is the dynamic yield stress of the backing target material. Plastic work rate is:

$$
\frac{d \mathrm{E}_{p}}{d t}=\pi h_{b} Y_{b} w\left(\frac{2}{3} h_{b}+\delta\right)
$$


The rate of change of the work done by the beams on the joint surface of the ceramic backing layer as shown in Fig. (9) is:

$$
\frac{d T}{d t}=\pi f_{b} \mathrm{R}^{2}{ }_{c} w
$$

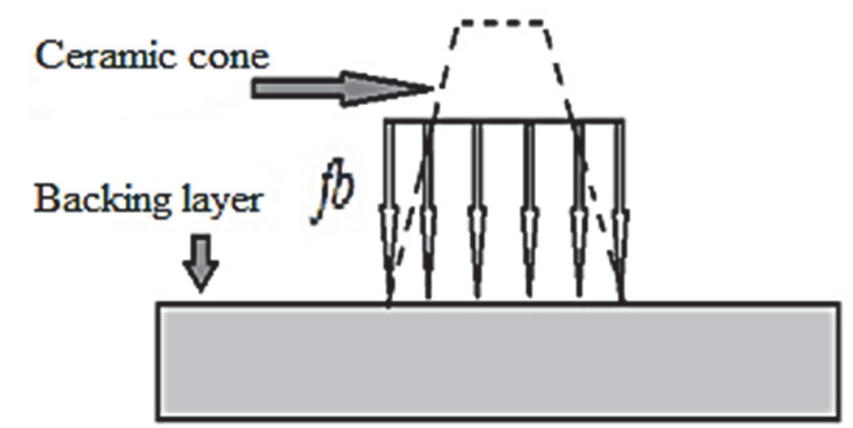

Figure 9: Ceramic cone and force applied to the backing layer [10].

where $\mathrm{W}$ is the surface velocity of the ceramic backing joint. Therefore, the kinetic energy conversion rate for the active region of the backing layer is:

$$
\frac{d E_{k}}{d t}=\pi \mathrm{R}^{2} h_{b} \rho_{b} w \frac{d w}{d t}
$$

Given the energy balance:

$$
\begin{aligned}
& \frac{d T}{d t}=\frac{d E_{p}}{d t}-\frac{d E_{k}}{d t} \\
& f_{b} R_{c}^{2}=b_{b} Y_{b}\left(\frac{2}{3} h_{b}+\delta\right)+R^{2} b_{b} \rho_{b} \frac{d w}{d t}
\end{aligned}
$$

From the above equation, we can calculate W. At very high impact velocities, the conical ceramics may be completely eroded, and therefore the projectile may come in contact with the back material. In this case, the actual behavior represents the speed difference between the projectile and the metallic material. Based on the Tate equations, the projectile motion equation can be modeled as follows:

$$
\frac{d v}{d t}=-\frac{Y_{b}+\frac{1}{2} \rho_{b}(v-w)^{2}}{\rho_{b}{ }^{L}}
$$

The equation of motion of the back material is given by the following Eqn. (17):

$$
\frac{d w}{d t}=\frac{\frac{1}{4} \pi Y_{b} \frac{D_{e q}^{2}}{4}-\pi h_{b} Y_{b}\left(\frac{2}{3} h_{b}+\delta\right)}{M_{b}}
$$

where $M_{b}$ is the effective mass of the area and is equal to: 


$$
M_{b}=\pi \rho_{b}\left\lceil R^{2} h_{b}-\frac{D_{e q}^{2}}{4}\left(b_{b}-b_{b t}\right)\right\rceil
$$

where $h_{b t}$ is the actual thickness of the center of the plate as shown in Fig. 10. Therefore, the analytical equations presented can calculate the projectile velocity and the velocity of the backing layer at any time interval. If the speed difference between them is zero, the projectile stops.
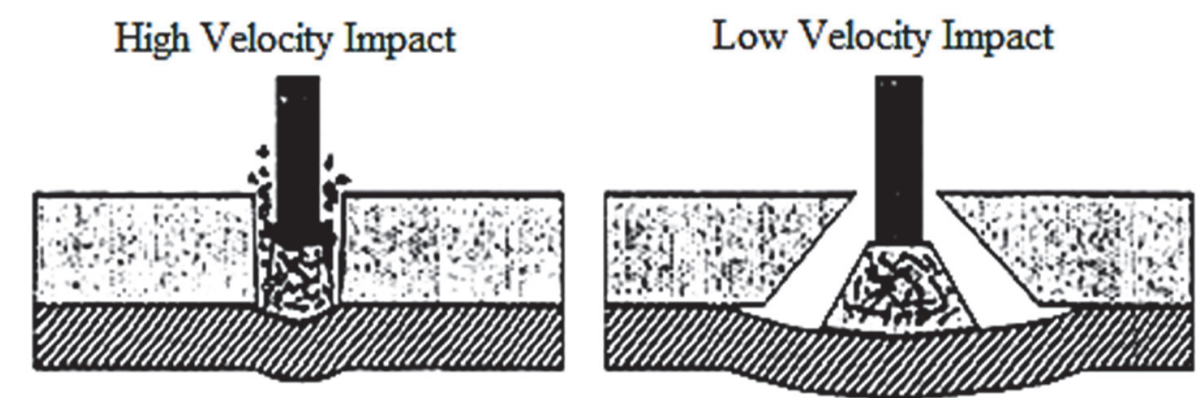

Figure 10: Full ceramic erosion and projectile contact with the back material [10].

There are two different yield criteria for defining full armor penetration in this model. The first criterion for cases where the speed is well above the speed of the ballistic limit. In this case, the projectile completely erodes the ceramic and exits the metal upon contact with the metal without causing any twist. In this case, the yield criterion is:

$$
h_{b t}=0
$$

The second criterion for states that are high enough to cause a significant twist in the metal (velocities close to the ballistic limit speed and slower than that). As can be seen in the numerical simulation, when the projectile speed is close to the metal velocity, failure occurs even when the full penetration of the ceramic or metal is not achieved. Therefore, in this case, a kinetic failure criterion is selected and the armor is assumed to fail when:

$$
v=w
$$

\section{Model by Fellows}

This model investigates the penetration of projectiles into thick armor with high velocities. The basis of this theory is the method of mass accumulation. Fig. (11) shows the schematic response of system mass accumulation. In this analysis, the joint surface between the projectile, the surface of the eroded projectile, the front ceramic surface, the surface of the eroded ceramic back, the surface of the eroded backing layer and the backing layer are considered [2].

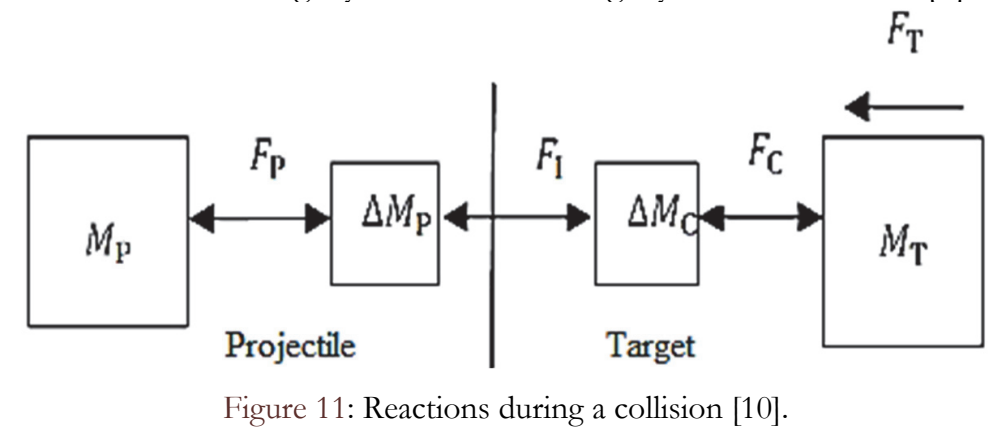

First, during high velocity impacts, the pressure at the joint surface of the ceramic projectile is greater than the erosive strength (a material required for erosion) of the projectile and thus the projectile is eroded. If the collision speed is high enough. The erosion strength of the ceramic will be excessive and the ceramic will also erode. As a result of projectile penetration in the ceramic, a conical crack is formed in the ceramic that transfers the load onto the backing layer. This is the case for ceramics. If the pressure at the ceramic joint surface of the backing layer is not high enough (less than the 
strength of the backing material's erosion), it is assumed that the projectile penetrates the ceramic and forms a smaller new cone. At the ceramic surface of the backing layer more than the erosive strength of the backing material, the ceramic cone begins to penetrate the backing material. Using mass accumulation theory, the basic equations of this theory can be written as follows: Newton's second law of the application for projectiles:

$$
F_{p}=-M_{p} X_{p}
$$

Newton's Second Law Application for Eroded Ceramic Front Panel:

$$
F_{1}-F_{c}=\frac{\Delta M_{c} \dot{X}_{C F}}{\Delta t}
$$

Projectile Mass Reduction:

$$
\Delta M_{p}=\left(\dot{X}_{p}-\ddot{X}_{C F}\right) \pi \rho_{c}
$$

Reduce ceramic mass from the ceramic front panel

$$
\Delta M_{c}=\left(\dot{X}_{C F}-\ddot{X}_{C}\right) \pi \rho_{C}
$$

Projectile forces when the projectile is eroded or mushrooming is formed:

$$
F_{P}=\sigma_{P E S}
$$

The relationship between ceramic front velocity, ceramic erosion, and ceramic velocity is:

$$
\dot{X}_{C F}=\dot{X}_{C E}+\ddot{X}_{C}
$$

The joint surface force $F_{1}$ will be different for different phases of erosion, mushrooming shape, and projectile rigidity. In the above equations $\dot{X}_{p}$ and $\ddot{X}_{p}$ projectile velocity and acceleration at any instant, $\dot{X}_{C F}$ ceramic front element speed, $\dot{X}_{C}$ ceramic element velocity, and $\sigma_{C E S}$ and $\sigma_{P E S}$ the erosion stresses are ceramic and projectile.

\section{Model by Forrestal and Luk}

Forrestal and Luk proposed a model for penetrating a projectile with a spherical nose. To calculate the force applied to the projectile during penetration, they must consider the effect of frictional force in addition to normal stress. To do this, the tangential stress was defined as follows [12]:

$$
\sigma_{t}=\mu \sigma_{n}
$$

where $\mu$ is the slip friction coefficient between the target material and the projectile.

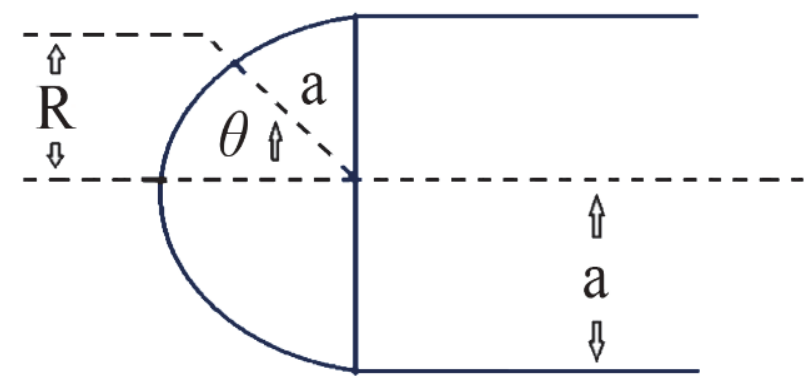

Figure 12: Cylindrical projectile with spherical nose [10]. 
According to Fig. (12), the forces resulting from normal and tangential stresses on the projectile nose can be obtained as follows:

$$
\begin{aligned}
& d F_{n}=2 \pi R a \sigma_{n}\left(V_{X} \cdot \theta\right) d \theta \\
& d F_{1}=2 \pi R a \mu \sigma_{n}\left(V_{X} \cdot \theta\right) d \theta
\end{aligned}
$$

This axial force enters on a projectile penetrating $V_{X}$ is equal to:

$$
F_{x}=\pi a^{2} \int_{0}^{\pi / 2} \sigma_{n}\left(V_{x} \cdot \theta\right)\left[\sin 2 \theta+2 \pi \sin ^{2} \theta\right] d \theta
$$

Given this equation, the axial force applied to the projectile with the spherical nose can be calculated for the time it hits the target vertically. Also, the normal stress on the projectile nose, in Eqn. (30), can be approximated by the radial stress on the surface and the velocity of the target particles at the joint surface of the target nose will be affected by the rigid projectile penetration at the velocity $V_{X}$ :

$$
V\left(V_{x} \cdot \theta\right)=V_{x} \cos \theta
$$

The depth of penetration of the projectile can then be calculated by obtaining the force applied to the projectile by Newton's law and the rigid equations of motion. The Forrestal model is one of the most widely used models of rigid penetration in targets and has been studied by many people. If the projectile nose shape is taken as a function of $y=y(x)$, the relationships are obtained as follows:

$$
\begin{aligned}
& N_{1}=1+\frac{8 \mu}{d^{2}} \int_{0}^{b} y d x \\
& N_{2}=N^{*}+\frac{8 \mu}{d^{2}} \int_{0}^{b} \frac{y y^{\prime 2}}{1+y^{\prime}} d x \\
& N^{*}=\frac{8}{d^{2}} \int_{0}^{b} \frac{y y^{3}}{1+y^{\prime}} d x
\end{aligned}
$$

where his the length of the projectile's nose. Also, a dimensionless parameter for different projectile shapes is defined as follows:

$$
\Psi=\frac{S}{d}
$$

when the projectile is ogive, $\Psi$ it is called the Caliber Radius Head. Thus, according to different projectile shapes and by using the Eqns. (37a) to (37c), the coefficients of shape can be obtained for different projectiles. This value for projectiles ogive in Fig. 13 is equivalent to:

$$
N_{1}=1+4 \mu \Psi^{2}\left[\left(\frac{\pi}{2}-\varphi_{0}\right)-\frac{\sin 2 \varphi_{0}}{2}\right]
$$




$$
\begin{aligned}
& N_{2}=\mu \Psi^{2}\left[\left(\frac{\pi}{2}-\varphi_{0}\right)-\frac{1}{3}\left(2 \sin 2 \varphi_{0}+\frac{\sin 4 \varphi_{0}}{4}\right)\right] \\
& N_{2}=\frac{1}{3 \Psi}-\frac{1}{24 \Psi^{2}} ; \quad 0<N^{*} \leq \frac{1}{2} \\
& \varphi_{0}=\sin ^{-1}\left(1-\frac{1}{2 \Psi}\right) ; \quad \Psi \geq \frac{1}{2}
\end{aligned}
$$

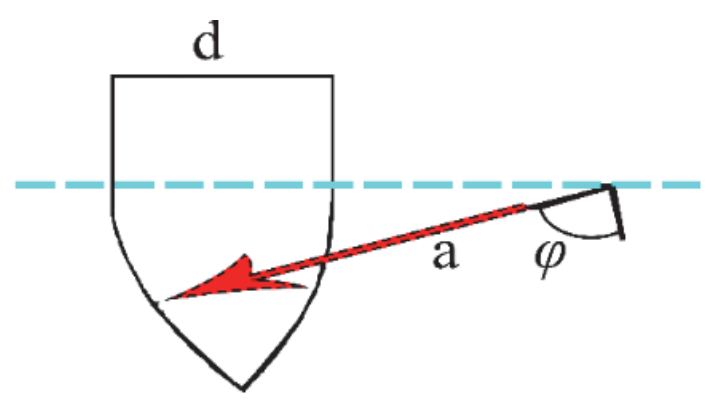

Figure 13: Projectile with ogive nose [10].

For flat nose projectiles in Fig. (14):

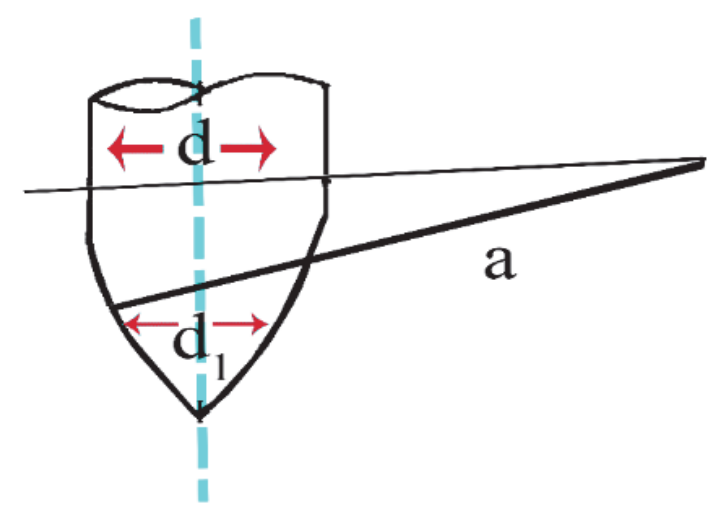

Figure 14: Ogive projectile with a flat nose [10].

$$
\begin{aligned}
& N_{1}=1+4 \mu \Psi^{3}\left[\left(\frac{\pi}{2}-\varphi_{0}\right)+\frac{\sin 2 \varphi_{0}}{2}-2\left(1-\frac{1}{2 \Psi}\right) \cos \varphi_{0}\right] \\
& N_{2}=\mu \Psi^{3}\left[\left(\frac{\pi}{2}-\varphi_{0}\right)+\frac{\sin 4 \varphi_{0}}{4}-\frac{8}{3}\left(1-\frac{1}{2 \Psi}\right) \cos ^{3} \varphi_{0}\right] \\
& N_{2}=\Psi^{3}\left[2 \cos ^{4} \varphi_{0}-\frac{8}{3}\left(1-\frac{1}{2 \Psi}\right)\left(2+\sin \varphi_{0}\right)\left(1-\sin \varphi_{0}\right)^{2}\right]+\zeta^{2} ; \zeta=\frac{d_{1}}{d}
\end{aligned}
$$




$$
\varphi_{0}=\sin ^{-1}\left[1-\frac{1}{2 \Psi}(1-\zeta)\right] ; \quad \Psi \geq \frac{1}{2}
$$

and finally, these shape coefficients are equal to one when the projectile is in the head.

$$
N_{1}=N_{2}=1
$$

$N_{2}$ is a function of $\Psi$ and is always $0<N_{2} \leq 1$. The smaller the $N_{2}$ content, the sharp the nose of the projectile, and vice versa. For example, this coefficient is equal to 1 for blunt head projectiles, and ogive projectiles it is smaller than 0.5.

\section{RESULTS AND DISCUSSION}

7 he rapid development of codes, especially in the field of impact, has allowed designers and engineers to design, manufacture and test new products and reduce testing costs. This software is widely used in defense areas that are usually cumbersome, expensive, and often limited. In the ballistic discussion of projectile penetration at different targets, the main focus in numerical simulation is on selecting the appropriate material model. However, other parameters such as element size, target thickness, impact velocity, and contact algorithm are effective in calculating the results. In this simulation, the ceramic plate is modeled with $50 \times 50 \times 50 \mathrm{~mm}$ dimensions. Designed in the form of a blunt head cylinder, the projectile is $10 \mathrm{~mm}$ thickness. In the mesh performed, $\mathrm{SiC}$ ceramics has 200,000 elements and 214,221 nodes and cylindrical steel bullets have 8000 elements and 9,261 nodes. The mesh performed has high accuracy in the ballistic limit results as shown in Fig. 14 after the projectile hit the target. In Fig. 15 the kinetic energy diagram of the projectile after impact in terms of the number of elements and Fig. 16 shows the depth of penetration in terms of the number of elements.

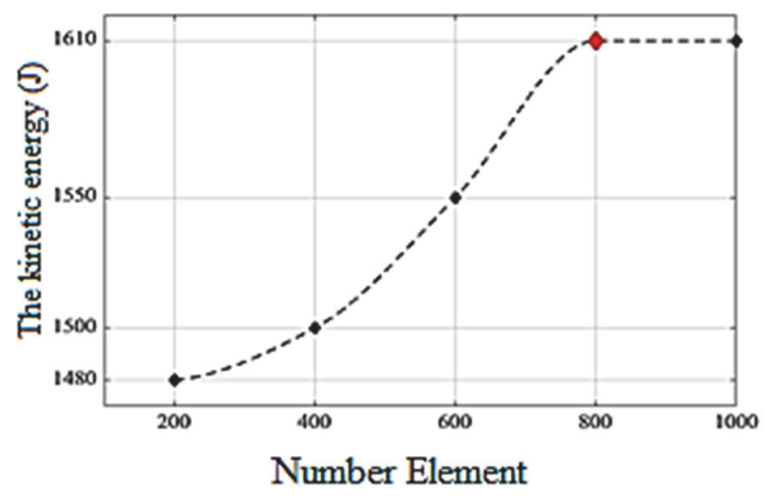

Figure 15: The kinetic energy diagram of the projectile after impact in terms of the number of elements.

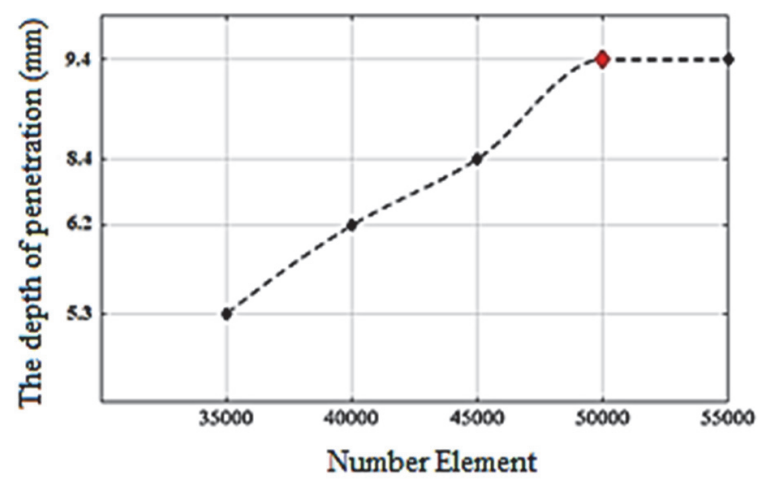

Figure 16: The depth of penetration in terms of the number of elements.

Fig. 17 shows the projectile impact on ceramic target at angles $0^{\circ}, 15^{\circ}, 30^{\circ}, 45^{\circ}$ at $1000 \mathrm{~m} / \mathrm{s}$ velocity and Fig. 18 shows the projectile collision velocity to time at different angles and Tab. 6 projectile weight specifications and target in each experiment shown. 


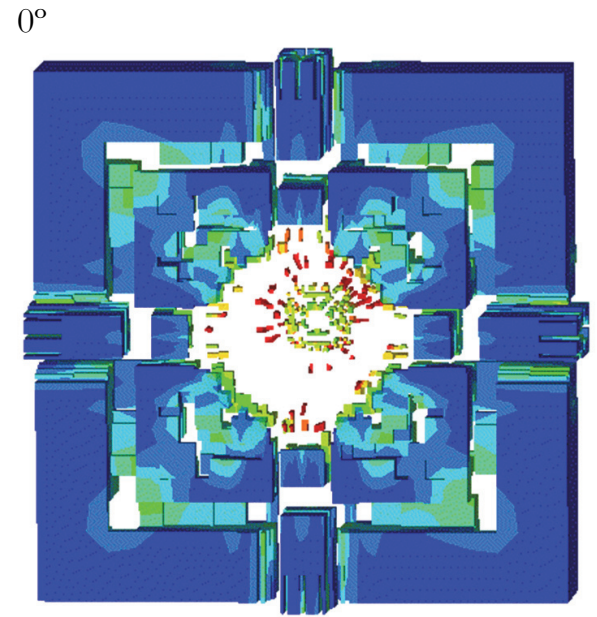

$30^{\circ}$

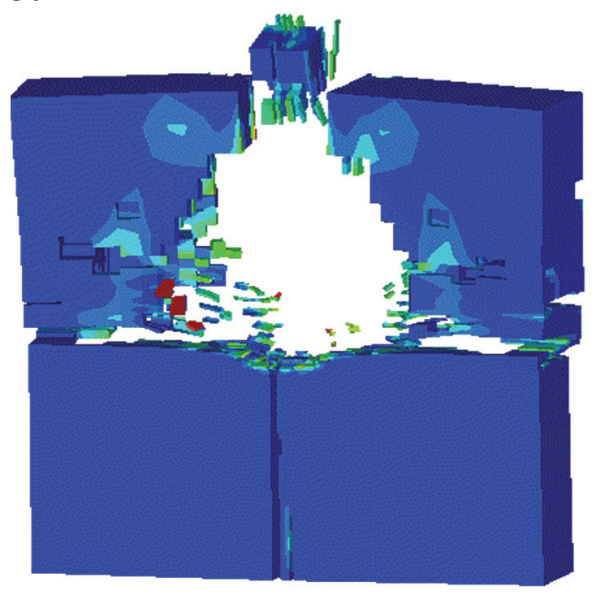

$15^{\circ}$

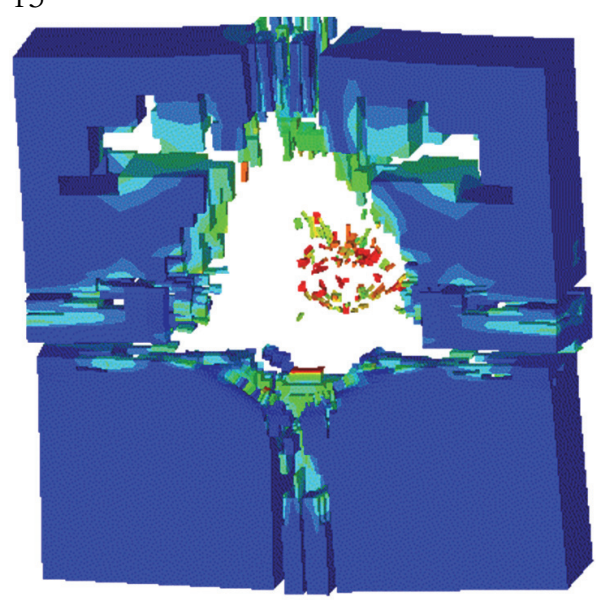

$45^{\circ}$

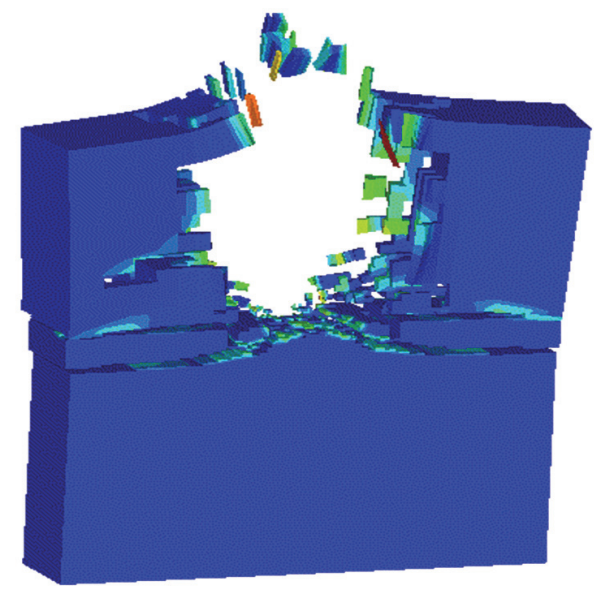

Figure 17: Projectile impact on ceramic target at different angles.

\begin{tabular}{rcccccc}
\hline Number & Collision velocity & Gas Gun & Explosive C4 & Sabot & Bullet & Ceramic \\
Test & $(\mathrm{m} / \mathrm{s})$ & (bar) & $(\mathrm{gr})$ & Weight (g) & weight (g) & weight (g) \\
1 & 273 & 120 & - & 4.1 & 12.15 & 200 \\
2 & 1000 & - & 6 & 4.2 & 12.13 & 200 \\
\hline
\end{tabular}

Table 6: Projectile weight specifications and targets in each experiment [10].

\begin{tabular}{lcccc}
\hline Collision angles (Degree) & $0^{\circ}$ & $15^{\circ}$ & $30^{\circ}$ & $45^{\circ}$ \\
$\begin{array}{l}\text { The thickness of the ceramic } \\
\text { layer (mm) }\end{array}$ & 20 & 20 & 20 & 20 \\
Numerical simulation (mm) & 9.8 & 8.9 & 7.2 & 6.1 \\
Experimental (mm) & 8.5 & 7.7 & 5.8 & 4.9 \\
Percentage error (\%) & 11.5 & 10.7 & 12.2 & 11.3 \\
\hline
\end{tabular}

Table 7: Comparison of the penetration depth of the ceramic target in each experiment [10]. 
$0^{\circ}$

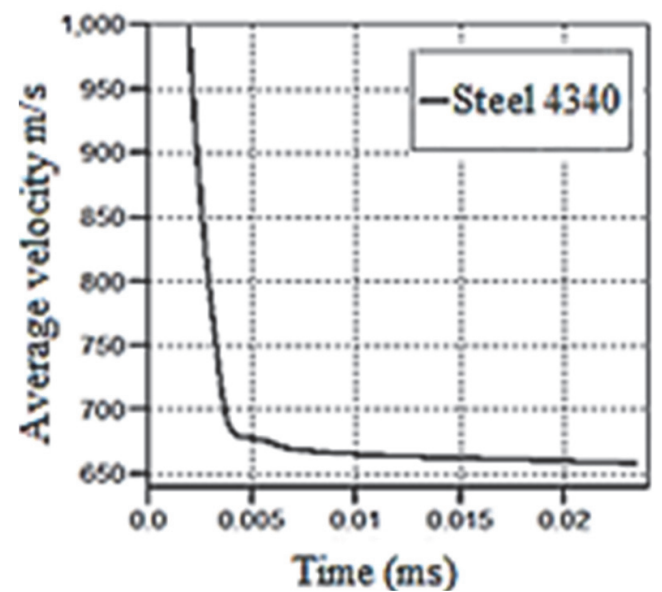

$30^{\circ}$

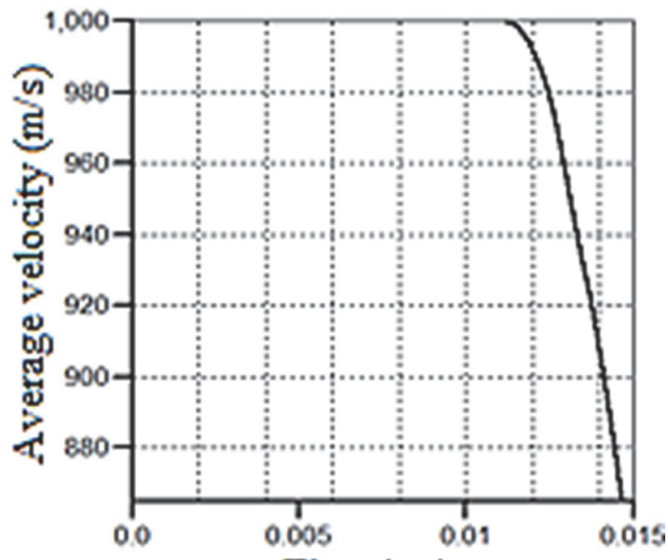

Time (ms) $15^{\circ}$

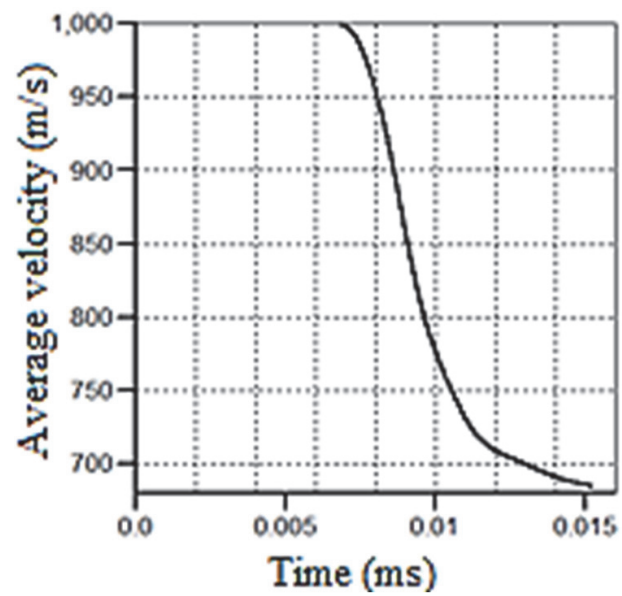

$45^{\circ}$

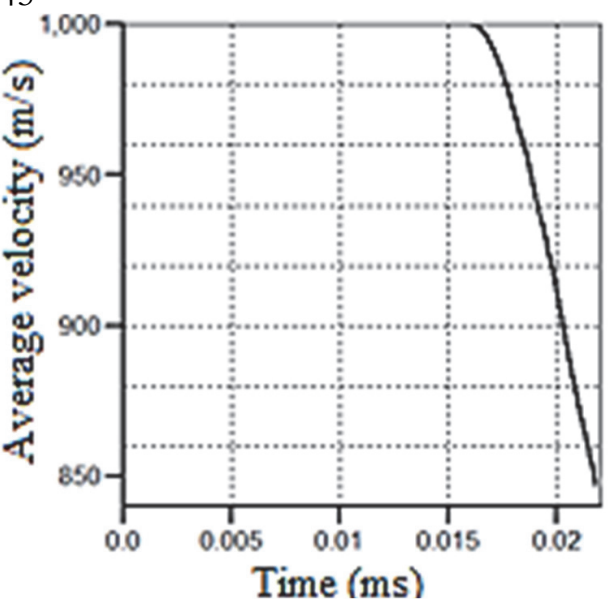

Figure 18: Projectile collision velocity to time at different angles.

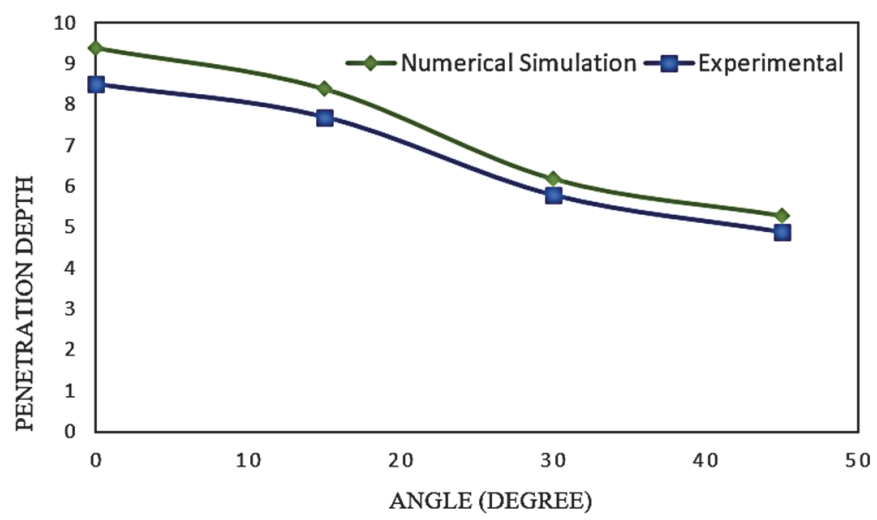

Figure 19: Comparison of the depth of penetration in numerical simulation and experimental data [10].

Tab. 7 shows the penetration depth of the ceramic target in each experiment and, as shown in the diagram in Fig. 19, as the angle of oblique decreases, the amount of penetration in the target decreases. Meshing and impact of the projectile on the ceramic target shown in Fig. 20. 


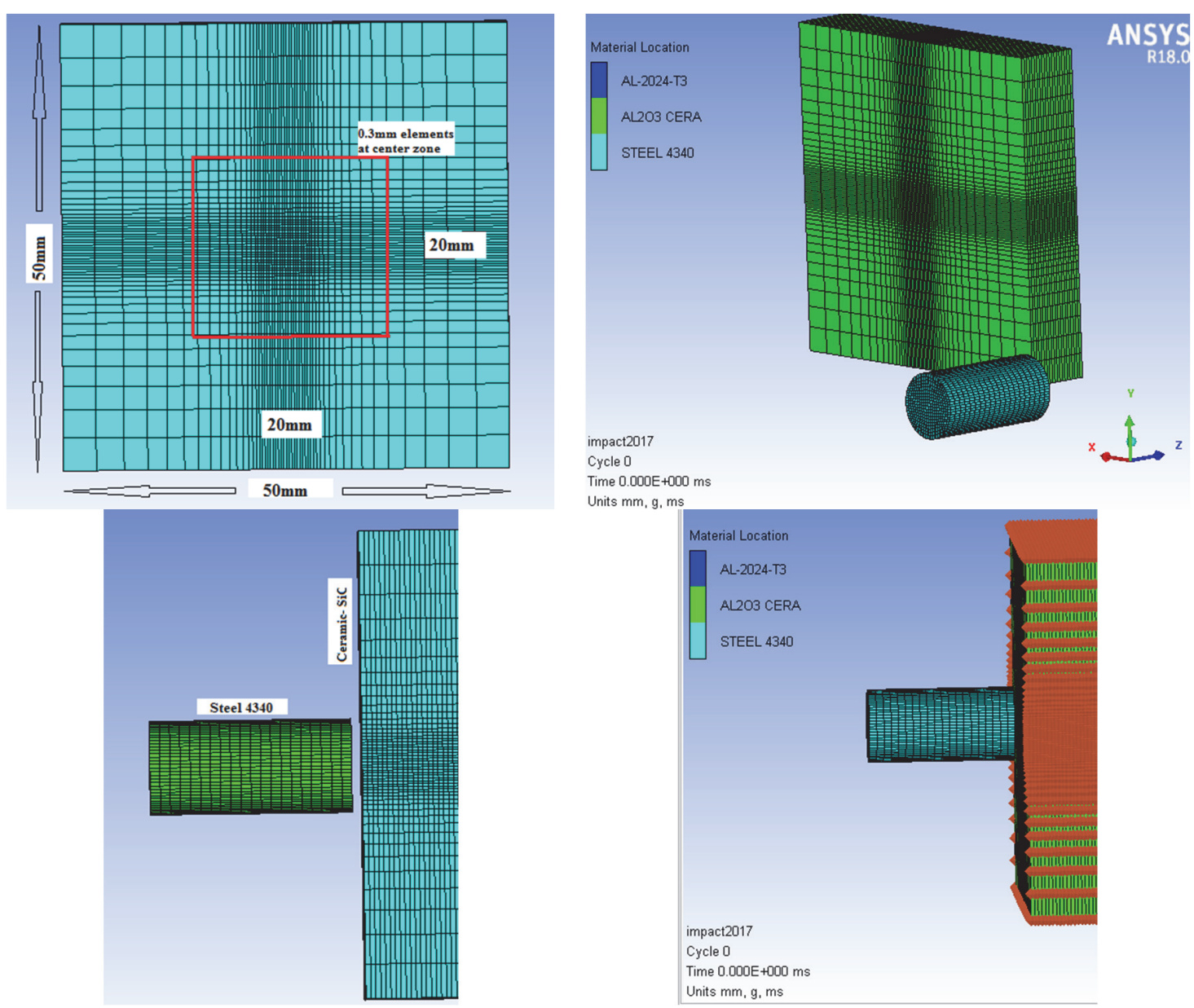

Figure 20: Meshing and the impact of the projectile on the ceramic target.

In contact between projectile and target, the most common type of contact is the definition of Contact Automatic Surface to Surface. Alongside this type of contact, there is also erosive contact. The problem with automatic contact for solid elements is that the projectile passes the target, but the elements that reach the ultimate stress and strain are not eliminated from the analysis. But with erosive contact, this problem can be resolved. In a projectile impact on a target, a threedimensional contact is defined as a type of erosive contact, which is the reason for selecting this contact, penetrating the projectile into the target, and removing the elements. The kinetic energy of the projectile is reduced by removing its elements. Tab. 8 shows the Characteristics of Johnson Cook's Material Model (JH-1) for ceramic purposes, Tab. 9 shows the Characteristics of Johnson Cook's Material Model (JH-1) for steel projectiles.

\section{CONCLUSIONS}

$\mathrm{U}$

sing the analytical equations and models presented in this paper as well as numerical simulation the following results are obtained.

1. By increasing the initial projectile velocity, the blunt projectile performance improves.

2. When a projectile hits a target, due to axial asymmetry, there is a torque on the plate that causes the projectile to deviate from its initial angle of impact. If the angle of impact of the projectile reaches the target, this torque can cause the projectile to have ricocheted off the target surface. All of these factors can lead to the complexity of analyzing and investigate oblique penetration processes.

3. The moment of impact, the Blunt projectile exhibits a higher surface area because of its brittle ceramics and fragile behavior, therefore, in the collision of the Blunt projectile, the surface is destroyed and the surface that is broken 
is greater and therefore less ballistic. It should be noted that this is true only for ceramics and crisp purposes in general, and for soft objects such as the opposite metals, this will be the case.

4. As the angle of the projectile increases, more than $45^{\circ}$ will reach Ricochet.

5. With the oblique impact at a given angle, the target velocity decreases with increasing target thickness, but this parameter is ineffective on the angle of change of direction.

6. When the projectile hits the target with a specified thickness, the residual velocity decreases as the angle of impact decreases, and the angle of change increases.

7. The behavior of the blunt projectile at high speeds is different.

8. As the oblique angle increases, the amount of penetration in the target decreases.

\begin{tabular}{|c|c|c|c|}
\hline Constant & Units & Constants & Units \\
\hline Density & $3.215\left(\mathrm{~g} / \mathrm{cm}^{3}\right)$ & Density & $7.83(\mathrm{~g} / \mathrm{cm} 3)$ \\
\hline Equation of state & Polynomial & Equation of state & Linear \\
\hline Bulk modulus, $\mathrm{K}_{1}$ & $1.84 \times 10^{8}(\mathrm{kPa})$ & Specific Heat & 477(J/kg.K) \\
\hline Pressure constant, $\mathrm{K}_{2}$ & $1.85 \times 10^{8}(\mathrm{kPa})$ & Shear modulus & $8.18 \times 10^{10} \mathrm{G}(\mathrm{Pa})$ \\
\hline Pressure constant, $\mathrm{K}_{3}$ & $1.57 \times 10^{8}(\mathrm{kPa})$ & Static ultimate strength & $9.5 \mathrm{e}+5(\mathrm{kPa})$ \\
\hline Strength model & $1.93 \times 10^{8}(\mathrm{kPa})$ & Strain hardness constant & $7.25 \mathrm{e}+5(\mathrm{kPa})$ \\
\hline Strength constant, A & $0.889(\mathrm{kPa})$ & Strain Hardness Strength & $0.014(\mathrm{~N})$ \\
\hline Strength exponent, $\mathrm{N}$ & $0.764(\mathrm{kPa})$ & Thermal softening power & $1.03(\mathrm{M})$ \\
\hline Strain rate constant, $\mathrm{C}$ & $0.0045(\mathrm{kPa})$ & Melting temperature & $1.790 \mathrm{TM}(\mathrm{K})$ \\
\hline Maximum fracture strength & $1(\mathrm{kPa})$ & Ref. strain rate & $1 \operatorname{EPSO}\left(\mathrm{s}^{-1}\right)$ \\
\hline Tensile limit & $-0.3 \times 10^{6}(\mathrm{kPa})$ & Failure parameter & 0.05(D1) \\
\hline Fracture strength constant, B & 0.29 & Failure parameter & 3.44(D2) \\
\hline Fracture strength exponent, $\mathrm{M}$ & 0.53 & Failure parameter & $-2.12(\mathrm{D} 3)$ \\
\hline Hugoniot's elastic limit & $6 \times 10^{6}(\mathrm{kPa})$ & Failure parameter & $0.002(\mathrm{D} 4)$ \\
\hline Damage constant, $\mathrm{d}_{1}$ & 0.005 & Yield stress & $7.92 \times 10^{8} \mathrm{~A}(\mathrm{~Pa})$ \\
\hline $\begin{array}{l}\text { Table 8: Characteristics of Johns } \\
\text { Model (JH-1) for ceramic }\end{array}$ & $\begin{array}{l}\text { Cook's Material } \\
\text { poses [18]. }\end{array}$ & $\begin{array}{l}\text { Table 9: Characteristics of } \\
\text { Material Model (JH-1) for }\end{array}$ & $\begin{array}{l}\text { ohnson Cook's } \\
\text { eel projectiles [18]. }\end{array}$ \\
\hline
\end{tabular}

\section{ACKNOWLEDGEMENTS}

$\mathrm{W}$

e thank the Imam Hussein University Laboratory for conducting a research test.

\section{REFERENCES}

[1] Woodward, R. L. (1990). A simple one-dimensional approach to modeling ceramic composite armor defeat, International Journal of Impact Engineering, 9(4), pp. 455-474. DOI: 10.1016/0734-743X(90)90035-T. 
[2] Fellows, N. A. and Barton, P. C. . (1999). Development of impact model for ceramic-faced semi-infinite armor, International Journal of Impact Engineering, 22(8), pp. 793-811. DOI: 10.1016/S0734-743X(99)00017-2.

[3] Shokrieh, M. M. and Javadpour, G. H. (2008). Penetration analysis of a projectile in ceramic composite armor, Composite Structures, 82(2), pp. 269-276. DOI: 10.1016/j.compstruct.2007.01.023.

[4] Florence, A. L. and Ahrens, T. J. (1967). Interaction of projectiles and composite armor. https://apps.dtic.mil/docs/citations/AD0652726.

[5] Zhang, X., Serjouei, A. and Sridhar, I. (2017). Criterion for interface defeat to penetration transition of long rod projectile impact on ceramic armor, Thin-Walled Structures. DOI: 10.1016/j.tws.2017.04.016.

[6] Yi, R.-c., Yin, L.-k., Wang, J.-r., Chen, Z.-g. and Hu, D.-q. (2017). Study on the performance of ceramic composite projectile penetrating the ceramic composite target, Defence Technology, 13(4), pp. 295-299.

DOI: $10.1016 /$ j.dt.2017.05.009.

[7] Brown, L. B., et al. (2017). Computational and Split-Hopkinson Pressure-Bar studies on the effect of the jacket during penetration of an AK47 bullet into ceramic armor . Materials \& Design 119, pp. 47-53.

DOI: 10.1016/j.matdes.2017.01.062.

[8] Das, S., Ronan, W., Wadley, H. N. G. and Deshpande, V. S. (2018). Penetration of confined ceramics targets, Extreme Mechanics Letters, 18, pp. 45-57. DOI: 10.1016/j.eml.2017.11.001.

[9] Savio, S. G. and Madhu, V. (2018). Ballistic performance evaluation of ceramic tiles for projectile velocity against hard steel projectile using the DOP test," International Journal of Impact Engineering. DOI: 10.1016/j.ijimpeng.2017.11.020.

[10] Moslemi Petrudi, A., Vahedi, Kh., Kamyab, M.H., Moslemi Petrudi, M.A. (2019). Numerical and Experimental Study of Oblique Penetration of Blunt Projectile into Ceramic-Aluminum Target. Modares Mechanical Engineering. https://mme.modares.ac.ir/article-15-20854-en.html.

[11] Xu, H. and Wen, H. M. (2016). A computational constitutive model for concrete subjected to dynamic loadings, International Journal of Impact Engineering, 91, pp. 116-125. DOI: 10.1016/j.ijimpeng.2016.01.003.

[12] Forrestal, M. J., Tzou, D. Y., Askari, E. and Long, D. B. (1995). Penetration into ductile metal targets with rigid sphericalnose rods, International Journal of Impact Engineering, 16(5), pp. 699-710. DOI: 10.1016/0734-743X(95)00005-U.

[13] Wang, B., Lu, G. and Lim, M. K. (1995). Experimental and numerical analysis of the response of aluminum oxide tiles to impact loading, Journal of Materials Processing Technology, 51(1), pp. 321-345.

DOI: 10.1016/0924-0136(94)01604-Y.

[14] Spigarelli, S. and Sandström, R. (2018). Basic creep modeling of aluminum, Materials Science and Engineering: A, 711, pp. 343-349. DOI: 10.1016/j.msea.2017.11.053.

[15] Goh, W. L., Zheng, Y., Yuan, J. and Ng, K. W. (2017). Effects of the hardness of steel on ceramic armor module against long rod impact, International Journal of Impact Engineering, 109. DOI: 10.1016/j.ijimpeng.2017.08.004.

[16] Wei, G. and Zhang, W. (2014). Perforation of thin aluminum alloy plates by blunt projectiles: An experimental and numerical investigation, Journal of Physics: Conference Series, 500(11), p. 112065.

DOI: $10.1088 / 1742-6596 / 500 / 11 / 112065$.

[17] Muñoz-Torrero, D. et al. (2018). Investigation of different anode materials for aluminum rechargeable batteries, Journal of Power Sources, 374, pp. 77-83. DOI: 10.1016/j.jpowsour.2017.11.032.

[18] Wang, X. and Shi, J. (2013). Validation of Johnson-Cook plasticity and damage using impact experiment. International Journal of Impact Engineering, 60, pp. 67-75 DOI: 10.1016/j.ijimpeng.2013.04.010.

[19] Senthil, K., Iqbal, M. A., Bhargava, P. and Gupta, N. K. (2017). Experimental and Numerical Studies on Mild Steel Plates against 7.62 API Projectiles, Procedia Engineering, 173, pp. 369-374. DOI: 10.1016/j.proeng.2016.12.032.

[20] Venkatesan, J., Iqbal, M. A. and Madhu, V. (2017). Ballistic Performance of Bilayer Alumina/Aluminum and Silicon Carbide/Aluminum Armors, Procedia Engineering, 173, pp. 671-678. DOI: 10.1016/j.proeng.2016.12.141.

[21] Wang, Q., Zhang, H., Cai, H., Fan, Q., Guoju, L., and Mu, X. (2017). Simulation analysis of co-continuous ceramic composite dynamic mechanical performance and optimization design. DOI: 10.1016/j.commatsci.2016.12.009.

[22] Corbett, G. G., Reid, S. R. and Johnson, W. (1996). Impact loading of plates and shells by free-flying projectiles: A review," International Journal of Impact Engineering, 18(2). DOI: 10.1016/0734-743X(95)00023-4. 
[23] Garcia, M. (1996). Ballistic Performance of Ceramic Faced Composite Plates (2nd Report), Journal of High-Pressure Institute of Japan, 34. DOI: 10.1016/j.mspro.2014.07.571.

[24] Zaera, R. and Sánchez-Galvez, V. (1998). Analytical modeling of normal and oblique ballistic impact on ceramic/metal lightweight armors, International Journal of Impact Engineering, 21(3), pp. 133-148.

DOI: $10.1016 /$ S0734-743X(97)00035-3.

[25] Chocron, S., Rodriguez, J. and Sanchez Galvez, A. (1997). A Simple Analytical Model to Simulate Textile Fabric Ballistic Impact. DOI: $10.1177 / 004051759706700707$.

[26] Awerbuch, J., Bodner, S. R. (1973). Analysis of the mechanics of perforation of projectiles in metallic plates, International Journal of Solids and Structures, 10, pp. 671-684. DOI: 10.1016/0020-7683(74)90050-X.

[27] Ravid, M., Bodner, S. R. (1994). Penetration into thick targets refinement of a 2D dynamic plasticity approach, International Journal of Impact Engineering, 15, pp. 491-499. DOI: 10.1016/0734-743X(94)80030-D. 